\title{
Effects of maternal conditions on early life history traits of black porgy Acanthopagrus schlegeli
}

\author{
Wen-Bin Huang ${ }^{1}$, Tai-Sheng Chiu ${ }^{1}$ and Chang-tai Shih ${ }^{2}$ \\ ${ }^{1}$ Institute of Zoology, National Taiwan University, Taipei, Taiwan, R.O.C.; ${ }^{2}$ Institute of Oceanography, National Taiwan University, \\ Taipei, Taiwan 106, R.O.C.
}

\begin{abstract}
Summary
This work examined the effects of maternal conditions on early life history traits of black porgy Acanthopagrus schlegeli. AgeII females produced significantly larger eggs as compared to the same size of Age-III females. Also, within each of the age groups, there was a positive relationship between egg size and female size. The larger eggs generally had larger volumes of oil globules, required longer incubation periods (hatching age), and produced larger larvae that endured longer to starvation. Hatching age was covaried negatively with yolk volume at hatching, indicating that embryonic development consumed primarily yolk as its energy resource. The condition factor, gonadosomatic index, hepatosomatic index, and lipid content of the females were not related to the early life history traits of their offspring.
\end{abstract}

\section{Introduction}

Concurrence of oceanographic conditions in favour of food production and first feeding of fish larvae is critical to their survival (Lasker 1981). Starvation may account for most of the larval mortality (Elliott 1986), and fasting endurance is of importance for their survival (Ojanguren et al. 1996). The size of larvae has been known to relate positively to the resistance to starvation (Hunter 1981; Marsh 1986; Miller et al. 1988). It is reasonable to assume that in unfavourable conditions, a larva with high fasting endurance has a better chance to overcome the situation than a larva with low endurance.

In the early life history of marine fish, larger eggs produce larger larvae that will subsist longer without food (Blaxter 1969; Hempel 1979; Hunter 1981). Larger eggs provide more energy for development (Hempel 1979), and larger larvae with more yolk might have a competitive advantage at birth (Lagomarsino et al. 1988). These initial size advantages of the larger larvae probably account for some increase in their early growth and survival (Henrich 1988; Hutchings 1991). Accordingly, egg size is an important factor contributing to the survival of early life stages of fish (Hinckley 1990). Although egg size is primarily determined genetically, it is also affected by other factors such as age and size of the mother (Springate et al. 1985). In some species of fish, older and heavier females produce larger eggs than younger and lighter females (Beacham and Murray 1985). As the mother's condition is one of the important factors that affect the survival of larvae, it should be explicitly considered when effects of egg size on the early life history traits are generalized (Chambers et al. 1989).

The black porgy, Acanthopagrus schlegeli, is widely distributed and considered as one of the valuable commercial species in many parts of Asia (Chang and Yueh 1990), particularly in Taiwan and Japan. It is one of the dominant species in the fish larval community in the coastal waters of western Taiwan (Huang and Chiu 1997). Embryonic and larval development of the black porgy have been described by Fukuhara (1987). In this study we intended to determine whether the maternal condition of black porgy affects egg size and early life history traits of their offspring.

\section{Materials and methods}

Thirty ripe females: black porgy, 16 Age-II fish and 14 Age-III fish, were collected in March 1997 and 1998 from the broodstock fish ponds at the Tainan Branch of Taiwan Fisheries Research Institute. They were unfed, acclimated in $600 \mathrm{~L}$ tanks for 2-3 days, and divided into five groups (blocks) for fertilization according to their time of ovulation. Eggs from each female were fertilized with milt from one male. The fertilized eggs were then transferred to two 1-L beakers to replicate the experiment. The acclimation of the females and the experiment with eggs and larvae were conducted at a temperature of $21 \pm 0.5^{\circ} \mathrm{C}$, salinity of $34 \pm 0.5 \%$, and photoperiod of $11-\mathrm{h}$ light and 13-h dark.

For each of the females, body weight and standard length were measured before fertilization; immediately thereafter the gonad, liver and other visceral organs were removed and weighed. The fish and visceral organs were then frozen. Later (within six weeks) samples were collected from the dorsal muscle, ventral muscle, and liver and their lipid contents determined by the method described by Folch et al. (1957). Maternal conditions studied were: (1) age (2) body size (3) condition factor (body weight/standard length ${ }^{3}$ ) (4) gonadosomatic index (gonad weight/body weight) (5) hepatosomatic index (liver weight/body weight) (6) ratio of visceral organ (excluding gonad and liver) weight to body weight, and (7) percentage contents of lipid in dorsal muscle, ventral muscle, and liver.

For eggs and larvae, seven early life history traits were examined: (1) egg volume (egg size) (2) oil globule volume in egg at the morula stage three hours after fertilization (3) hatching age (incubation period of egg) (4) body length of hatchling (larva immediately after hatching) (5) yolk volume of hatchling (6) oil globule volume of hatchling, and (7) life span of larva. Egg volume, oil globule volume of egg and oil globule volume of hatchling were estimated by measuring their diameters. Hatchlings were anaesthetized in the $300 \mathrm{mg} \mathrm{L}^{-1}$ 2-phenoxyethanol solution and their body length, length and height of yolk, and diameter of oil globule were measured. Because the yolk of a hatchling is oval in shape, its volume was estimated by its length and height, and subtracted from the volume of oil globules it 
contained. The larvae were unfed during the experiment, and the duration (days) between the time of hatching and the time of death of a larva was recorded as its larval life span, the endurance level to starvation.

The relationship between pairs of traits was assessed by the coefficient of partial correlation. A two-stage nested design, with 30 females nested under 5 groups of fertilization, was used to determine the female's effect on each of the early life history traits (Montgomery 1997). The percentages of the total variance due to the female source were compared among the early life history traits. The effects of maternal condition on early life history traits were assessed by the coefficient of simple correlation. In addition, the relationship of a female's condition to her egg size was determined by multiple linear regression analysis.

Prior to analysis we logged transformed egg volume, oil globule volume in egg, and yolk and oil globule volumes of each hatchling. Two-stage nested design, variance components in ANOVA, and partial and simple correlations were performed and estimated using SAS (SAS Institute, Inc. 1987).

\section{Results}

The egg volumes from 30 females ranged between 0.254 and $0.403 \mathrm{~mm}^{3}$ with a mean \pm standard deviation of $0.325 \pm$ $0.031 \mathrm{~mm}^{3}(n=900)$. The variations in egg volume and its oil globule volume were fairly similar with the coefficient of variation $(\mathrm{CV}$, standard deviation/mean) of 0.09 and 0.11 , respectively. The variations were high for yolk volume and oil globule volume of each hatchling $(\mathrm{CV}=0.15$ and 0.16$)$, and low for hatching age, body length of hatchling, and life span of larva $(\mathrm{CV}=0.04,0.04$, and 0.06)

There were eight significant coefficients of partial correlation between early life history traits (Fig. 1). Oil globule volume in egg, incubation period, body length of hatchling, and yolk volume of the hatchling were covaried with egg volume. Yolk volume of the hatchling increased with increasing oil globule volume of the hatchling but decreased with increasing hatching age. Oil globule volumes of hatchling and egg were correlated. Body length of the hatchling was the only trait that covaried with the larval life span. Compared to smaller eggs, larger eggs had larger oil globule volumes, longer incubation periods for hatching, and produced larger larvae, which had larger energy reserves (i.e. yolk and oil globule) to endure longer to starvation. The above findings indicated that egg volume was the most important early history trait which determined most of the other traits for black porgy. The negative correlation between yolk volume of hatchling and hatching age suggest that yolk, not oil globule in the yolk, is the main energy source for the embryonic development.

Each of the early life history traits varied significantly among the 30 females, however, not the blocks of fertilization (Table 1). The percentage of variance due to maternal parents was greater for egg volume and hatching age (Table 2). None of the early life history traits was significantly related to the size of the mother $(\mathrm{P}>0.05)$ when the two age groups were combined. When the age factor was statistically removed by linear regression, egg volume, hatching age, and body length and yolk volume of hatchling were significantly positively correlated to standard length and body weight of females (Table 2). Also, the larval life span was significantly positively correlated to the ratio of visceral organ weight to body weight of the females, which was mainly due to high content of fat tissue around the intestine. No significant correlation was found between other maternal conditions (condition factor, gonadosomatic index, hepatosomatic index, and the lipid contents of muscles and liver) and the early life history traits of the offspring (Table 2).

The multiple regression equation between egg volume (Y, dependent variable) and age $\left(\mathrm{X}_{1}\right)$ and body weight $\left(\mathrm{X}_{2}\right)$ of females (independent variables) was expressed by $\mathrm{Y}=247.1$ $76.0 \mathrm{X}_{1}+0.260 \mathrm{X}_{2}-0.016 \mathrm{X}_{1} \mathrm{X}_{2}$, where if Age-II then $\mathrm{X}_{1}=0$ and if Age-III then $\mathrm{X}_{1}=1$ (d.f. $=3,896, R^{2}=0.459, F$-value $=$ 253.5, $\mathrm{P}=0.000$ ). This equation showed that when the 30 females were divided into Age-II and Age-III groups, within each of the age groups there was a significantly regressive relationship between egg volume and female body weight (Fig. 2). Analysis of covariance suggested that the slopes of the regression lines of the two age groups were not significantly different $($ d.f. $=1,896, F$-value $=0.684, \mathrm{P}=0.408)$, but that the elevations of the two lines were significantly different $($ d.f. $=1,896, F$-value $=57.80, \mathrm{P}=0.000)$. In other words, Age-II females produced larger eggs per unit of body weight than Age-III females.

\section{Discussion}

Egg size

The results of this study demonstrated that the black porgy larvae from large eggs with large oil globules had longer incubation periods and had larger size and yolk reserves at hatching than those from small eggs (Fig. 1). The positive relationship of body length and yolk volume of hatchlings to egg size has been documented in several species of fish (Miller et al. 1995; Chambers and Leggett 1996), particularly in salmonids (Springate and Bromage 1985; Lagomarsino et al. 1988), but a few studies reported no such correlation (Reagan and Conley 1977; Bengston et al. 1987, Lagomarsino et al. 1988). In contrast to the absence of association between size of egg and incubation period and between initial yolk volume in eggs and hatching size (Blaxter 1988), these associations were distinct in the black porgy (Fig. 1), similar to the findings in the capelin by Chambers et al. (1989).

Temporal matching of resources and consumers is critical to the survival of fish larvae (Lasker 1981). High fasting endurance should increase the chance of encountering suitable food before the onset of irreversible starvation, and increase the chance of survival (Chambers et al. 1989). Offspring performance traits are positively size-dependent (Marsh 1986; Sinervo and McEdward 1988; Sinervo 1990). Larvae hatched from relatively large eggs with more yolk might have a competitive advantage at birth over larvae from smaller eggs with less yolk (Blaxter and Hempel 1963; Bagenal 1969; Lagomarsino et al. 1988). Also, larger larvae are less restricted to the timing of first feeding and the size of prey (Miller et al. 1995). In this study, the longer life span of starved larvae of the black porgy with the trait of large hatchling sizes (Fig. 1) agreed with most of the previous reports that body size is positively related with the resistance to starvation (Hunter 1981; Marsh 1986; Miller etal. 1988). In addition, the successful initiation of feeding of fish larvae is considerably affected by their size and condition, such as the amount of their energy reserves (Heming 1982). Also, their predation pressure is negatively correlated with their size (Miller et al. 1988). Reduction in larval size at hatching was considered to be analogous to a sublethal response (Rosenthal and Alderdice 1976). The initial size advantage of fish larvae probably accounts for some of the increase in their early survival and growth (Henrich 1988; Hutchings 1991).

It has been proposed by numerous authors that egg size influences larval survival through its effect on larval size, growth 


\section{yolk volume at hatching}
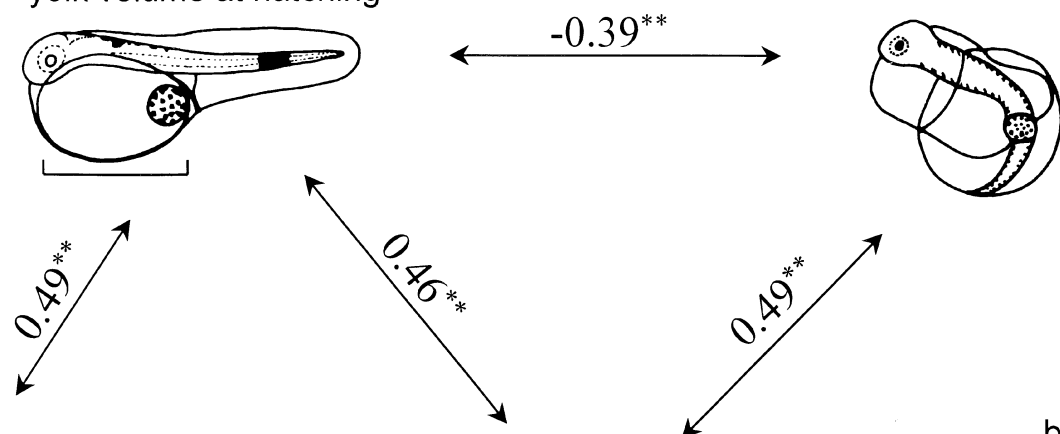

age at

hatching

oil globule volume at hatching
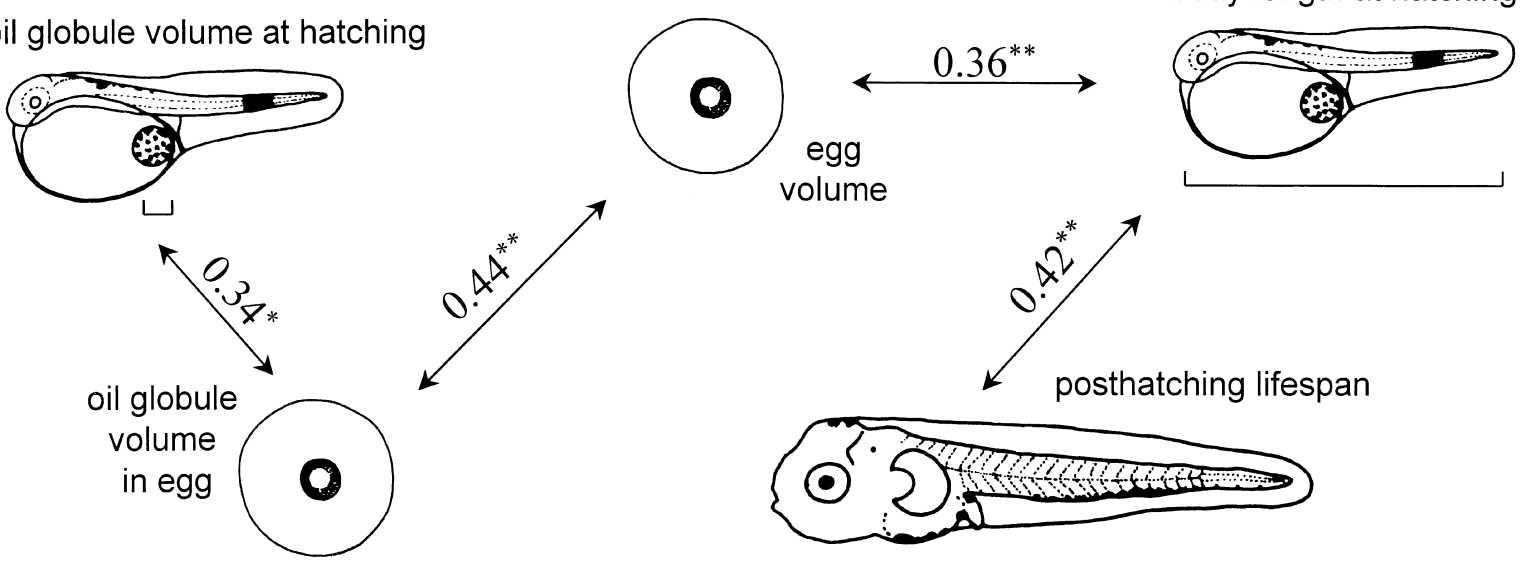

volume

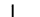

Fig. 1. Partial correlations between early life history traits of the black porgy, Acanthopagrus schlegeli. Only significant correlations are shown $(\mathrm{P}<0.05$, d.f. $=53)$

Table 1

Analysis of variance table for the effects of fertilized blocks and females on egg volume (EV), oil globule volume in egg (OVE), hatching age (AGE), body length at hatching $(\mathrm{BL})$, yolk volume at hatching (YV), oil globule volume at hatching $(\mathrm{OVH})$, and life span (LS) of black porgy, Acanthopagrus schlegeli

\begin{tabular}{|c|c|c|c|c|c|}
\hline $\begin{array}{l}\text { Source of } \\
\text { variation }\end{array}$ & $\begin{array}{l}\text { Sum of } \\
\text { squares }\end{array}$ & $\mathrm{df}$ & Mean square & F-ratio & P-value \\
\hline \multicolumn{6}{|l|}{ EV } \\
\hline blocks & 0.676 & 4 & 0.169 & 0.75 & 0.566 \\
\hline females (within blocks) & 5.616 & 25 & 0.225 & 120.94 & 0.000 \\
\hline Error & 1.616 & 870 & 0.002 & & \\
\hline \multicolumn{6}{|l|}{ OVE } \\
\hline blocks & 1.075 & 4 & 0.269 & 1.48 & 0.239 \\
\hline females (within blocks) & 4.546 & 25 & 0.182 & 24.61 & 0.000 \\
\hline Error & 6.430 & 870 & 0.007 & & \\
\hline \multicolumn{6}{|l|}{ AGE } \\
\hline blocks & 264.5 & 4 & 66.12 & 1.18 & 0.342 \\
\hline females (within blocks) & 1397.4 & 4 & 55.89 & 124.00 & 0.000 \\
\hline Error & 392.2 & 870 & 0.45 & & \\
\hline \multicolumn{6}{|l|}{$\mathrm{BL}$} \\
\hline blocks & 0.309 & 4 & 0.077 & 0.53 & 0.718 \\
\hline females (within blocks) & 3.674 & 25 & 0.147 & 39.70 & 0.000 \\
\hline Error & 3.220 & 870 & 0.004 & & \\
\hline \multicolumn{6}{|l|}{ YV } \\
\hline blocks & 0.920 & 4 & 0.230 & 0.56 & 0.697 \\
\hline females (within blocks) & 10.368 & 25 & 0.415 & 40.92 & 0.000 \\
\hline Error & 8.817 & 870 & 0.010 & & \\
\hline \multicolumn{6}{|l|}{$\mathrm{OVH}$} \\
\hline blocks & 3.430 & 4 & 0.858 & 2.39 & 0.077 \\
\hline females (within blocks) & 8.954 & 25 & 0.358 & 28.72 & 0.000 \\
\hline Error & 10.852 & 870 & 0.012 & & \\
\hline \multicolumn{6}{|l|}{ LS } \\
\hline blocks & 2.167 & 4 & 0.542 & 0.16 & 0.956 \\
\hline females (within blocks) & 84.183 & 25 & 3.367 & 31.19 & 0.000 \\
\hline Error & 93.912 & 870 & 0.108 & & \\
\hline
\end{tabular}


Table 2

Percentage of total variance in each early life history trait due to maternal effect, and coefficients ( $r$-value) of correlation of the traits to maternal conditions of the black porgy (SL, standard length; BW, body weight, CF, condition factor; GSI, gonadosomatic index; HSI, hepatosomatic index; RVB, ratio of visceral organ (excluding gonad and liver) weight to (BW)

\begin{tabular}{|c|c|c|c|c|c|c|c|}
\hline & $\begin{array}{l}\text { Egg } \\
\text { vol. }\end{array}$ & $\begin{array}{l}\text { Oil globule } \\
\text { vol. in egg }\end{array}$ & $\begin{array}{c}\text { Age at } \\
\text { hatching }\end{array}$ & $\begin{array}{l}\text { Length at } \\
\text { hatching }\end{array}$ & $\begin{array}{l}\text { Yolk vol. } \\
\text { at hatching }\end{array}$ & $\begin{array}{l}\text { Oil globule vol. } \\
\text { at hatching }\end{array}$ & $\begin{array}{l}\text { Posthatching } \\
\text { lifespan }\end{array}$ \\
\hline 1) $\%$ variance & 71.02 & 37.73 & 68.03 & 51.00 & 51.57 & 38.54 & 46.70 \\
\hline \multicolumn{8}{|l|}{ 2) Maternal size } \\
\hline SL & $0.74 * *$ & 0.26 & $0.47 * *$ & $0.43^{*}$ & $0.45^{*}$ & 0.07 & 0.32 \\
\hline BW & $0.75^{* *}$ & 0.35 & $0.48 * *$ & $0.41 *$ & $0.42 *$ & 0.20 & 0.18 \\
\hline 3) $\mathrm{CF}$ & -0.16 & 0.07 & 0.03 & -0.32 & -0.23 & 0.08 & -0.33 \\
\hline 4) GSI & 0.12 & 0.11 & 0.33 & -0.30 & $-0.22 *$ & 0.16 & -0.13 \\
\hline 5) HSI & -0.11 & -0.34 & -0.05 & 0.08 & -0.03 & 0.06 & -0.07 \\
\hline 6) RVB & -0.05 & 0.12 & -0.35 & 0.33 & 0.11 & 0.19 & $0.50^{* *}$ \\
\hline \multicolumn{8}{|l|}{ 7) Crude Lipid (\%) } \\
\hline Dorsal muscle & -0.20 & -0.33 & -0.03 & -0.29 & 0.20 & 0.22 & -0.11 \\
\hline Ventral muscle & -0.13 & -0.30 & 0.03 & 0.04 & 0.19 & 0.17 & -0.04 \\
\hline Liver & -0.18 & 0.06 & -0.03 & -0.25 & 0.01 & 0.35 & -0.09 \\
\hline
\end{tabular}

* Significant at $5 \%$ level $(P<0.05)$.

** Significant at $1 \%$ level $(P<0.01)$.

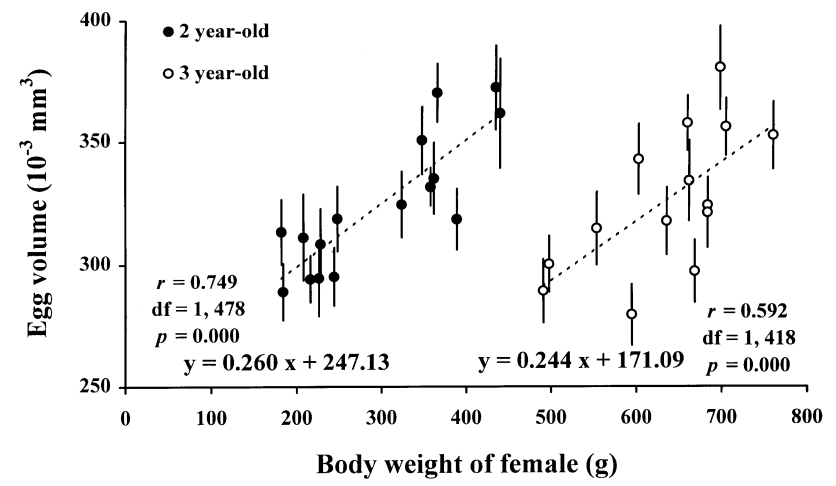

Fig. 2. A plot of egg volume (mean \pm 1 standard deviation) on body weight of its mother in two year classes of the black porgy

rate, mouth size, and length of time from hatching to starvation (Blaxter and Hempel 1963; Bagenal 1969; Ware 1975; Knutsen and Tilseth 1985). Larger eggs provide more energy for growth and development and generally produce larger larvae which are able to avoid predators more effectively, survive longer without feeding, search through a larger volume of water for prey, and eat prey of a greater variety of sizes (Hinckley 1990). If growth rates are positively related to initial body size (Ojanguren et al. 1996), larger larvae will spend less time at the most vulnerable sizes (Miller et al. 1988). Large size also provides a potential advantage in competition for territory (Huntingford et al. 1990). On the other hand, larger eggs take more time to incubate (Chambers et al. 1989; Wootton 1994; this study). If egg predation is size dependent or daily mortality rate is higher in the embryonic than in the larval period, producing large eggs and an extended embryonic period are seen as the cost for being large at hatching (Chambers et al. 1989; Miller et al. 1995).

\section{Age and size of mother}

Variation in the sizes of marine fish eggs has been associated with numerous factors including latitude, temperature, salinity, egg batch sequence, availability of food for larvae, seasons of spawning, years, population origin, and status of maternal parent (Bagenal 1971; Springate and Bromage 1985; Crisp 1994). Differences in egg size are thought to reflect adaptations by the spawning stock to varying conditions met by early larvae (Hinckley 1990). Maternal effects on egg size have been reported for a number of marine and freshwater species of fish (Chambers and Waiwood 1996). In this study, within the same age of black porgy, larger size fish produced larger size eggs (Table 1, Fig. 2). In numerous studies the egg size-female parental size relationships have been documented (Hinckley 1990). By contrast, Wootton (1992) stated that in teleosts generally, there is only a weak relationship between maternal body size and egg size, except in some fishes such as Salmonidae. However, the larvae from larger parents could have inherited higher growth rates (Ojanguren et al. 1996). The offspring from larger parents with initial size advantage at hatching and with inherited higher growth rates are in favour of survival.

\section{Nutritional status of mother}

The difference in nutritional status of rainbow trout caused the differences in egg number, diameter and chemical composition of the eggs, and their hatchability (Springate et al. 1985). Nutritional status of fish is related to the food levels experienced before. Evidence of the positive effects of female ration and condition factor (Fulton's $k$ ) on egg size was reported by Hislop et al. (1978) and Chambers and Waiwood (1996), respectively. Chambers and Leggett (1996) concluded that maternal effects on offspring are significantly modulated by the environment experienced, including water temperature and food levels, by the female before reproduction.

In this study, most of the conditions of mothers were unrelated to egg size and other early life history traits, but the ratio of visceral organ weight and body weight was related to the life span of the starved larvae (Table 2). This indicated that the lipid stored around the organs was an important contribution to the fasting endurance because the high weight ratio was due mainly to the increasing lipid tissue content around the intestine. Chambers et al. (1989) also found that an increase in oil globule volume of hatchlings extended the time of survival under starvation in larvae. However, Chambers and Waiwood (1996) suggested that detecting a condition effect on egg size may require more direct and sensitive measures of condition. Hinckley (1990) argued that gonad and liver are not particularly sensitive indicators of condition in fish and use of the measures of these organs may have obscured a correlation between egg 
size and female parental size or conditions. Therefore, a possible explanation for most conditions of the maternal parent when, unrelated to egg size and other early life history traits, was that the conditions of the maternal parents used in this study were not sensitive enough to reflect the condition of oogenesis of the fish.

In conclusion, larger females (within the same age, i.e. with higher growth rates) produce larger eggs which produce larger larvae with more energy available for initial growth (larger yolk reserves) and have higher resistance to starvation. Choice of the adult fish with high growth rate within a year-class to produce large offspring for size advantage and with considerably higher fecundity to produce more eggs, may be considered for the broodstock of the black porgy in aquaculture.

\section{Acknowledgements}

We are grateful to Dr Y. Y. Ting, Mr S. L. Yeh, Mr Y. T. Chu and Mr J. R. Hseu of the Tainan Branch, TFRI for donating the fish used and offering assistance in this study, and Dr W. L. Liao and Dr C. M. Kuo of the Institute of Fisheries Science, National Taiwan University for their suggestions and assistance in lipid extraction. The authors also wish to thank Dr C. F. Tsai and two anonymous referees for reading and commenting on the manuscript.

\section{References}

Bagenal, T. B., 1969: The relationship between food supply and fecundity in brown trout Salmo trutta L. J. Fish Biol. 1, 169-182.

Bagenal, T. B., 1971: The interrelation of the size of fish eggs, the date of spawning and the production cycle. J. Fish Biol. 3, 207-219.

Beacham, T. D.; Murray, C. B., 1985: Effect of female size, egg size, and water temperature on developmental biology of chum salmon (Oncorhynchus keta) from the Nitinat river, British Columbia. Can. J. Fish. Aquat. Sci. 42, 1755-1765.

Bengston, D. A.; Barkman, R. C.; Berry, W. J., 1987: Relationship between maternal size, egg diameter, time of spawning season, temperature, and length at hatch of Atlantic silverside, Menidia menidia. J. Fish. Biol. 31, 697-704.

Blaxter, J. H. S., 1969: Development: eggs and larvae. In: Fish physiology, Vol. 3. W. S. Hoar and D. J. Randall (eds), Academic Press, New York., pp. 177-252.

Blaxter, J. H. S., 1988: Pattern and variety of development. In: Fish physiology, Vol. 11a. W. S. Hoar and D. J. Randall (eds), Academic Press, New York., pp. 1-58.

Blaxter, J. H. S.; Hempel, G., 1963: The influence of egg size on herring larvae (Clupea harengus L. ). J. Cons. Perm. Int. Explor. Mer. 28, 211-240.

Chambers, R. C.; Leggett, W. C., 1996: Maternal influences on egg size variation in marine temperate fishes. Am. Zool. 36, 180-196.

Chambers, R. C.; Leggett, W. C.; Brown, J. A., 1989: Egg size, female effects, and the correlations between early life history traits of capelin, Mallotus villosus: an appraisal at the individual level. Fish. Bull. U.S. 87, 515-523.

Chambers, R.C.; Waiwood, K. G., 1996: Maternal and seasonal differences in egg sizes and spawning characteristics of captive Atlantic cod, Gadus morhua. Can. J. Fish Aquat. Sci. 53, 1986-2003.

Chang, C. F.; Yueh, W. S., 1990: Annual cycle of gonadal histology and steroid profiles in the juvenile males and adult females of the protandrous black porgy, Acanthopagrus schlegeli. Aquaculture 91, 179-196.

Crisp, D. T., 1994: Reproductive investment of female brown trout, Salmo trutta L., in a Stream and Reservoir System in Northern England. J. Fish Biol. 44, 343-349.

Elliott, J. M., 1986: Spatial distribution and behavioural movements of migratory trout Salmo trutta in a lake district stream. J. Anim. Ecol. 55, 907-922.

Folch, J.; Lee, M.; Stanley, G. S. H., 1957: A simple method for the isolation and purification of total lipids from animal tissues. J. Biol. Chem. 226, 497-507.
Fukuhara, O., 1987: Larval development and behavior in early life stages of black sea bream reared in the laboratory. Nippon Suisan Gakkaishi 53, 371-379.

Heming, T. A., 1982: Effects of temperature on utilization of yolk by chinook salmon (Oncorhychus tshawytscha) eggs and alevins. Can. J. Fish. Aquat. Sci. 39, 184-190.

Hempel, G., 1979: Early life history of marine fish. The Egg Stage University of Wash. Press, Seattle. 70pp.

Henrich, S., 1988: Variation in offspring sizes of the poeciliid fish Heterandria formosa in relation to fitness. Oikos 51, 13-18.

Hinckley, S., 1990: Variation of egg size of walleye pollock Theragra chalcogramma with a preliminary examination of effect of egg size and larval size. Fish. Bull. U.S. 88, 471-483.

Hislop, J. R. G.; Robb, A. P.; Gauld, J. A., 1978: Observations on effects of feeding level on growth and reproduction in haddock, Melunogrammus aeglefinus (L.) in captivity. J. Fish Biol. 13, 85-98.

Huang, W. B., Chiu, T. S., 1997: Environmental factors associated with the occurrence and abundance of larval porgies, Acanthopagrus latus and Acanthopagrus schlegeli, in the coastal waters of western Taiwan. Acta Zool. Taiwanica 8, 19-32.

Hunter, J.R., 1981: Feeding ecology and predation of marine fish larvae. In: Marine fish larvae. R. Lasker (ed.) Washington Sea Grant Program, Seattle., pp. 33-77.

Huntingford, F. A.; Metcalfe, N. B.; Thorpe, J. E.; Graham, W. D.; Adams, C. E., 1990: Social dominance and body size in Atlantic salmon parr, Salmo salar L. J. Fish Biol. 36, 877-881.

Hutchings, J. A., 1991: Fitness consequences of variation in egg size and food abundance in brook trout Salvelinus fontinalis. Evolution 45, 1162-1168.

Knutsen, G. M.; Tilseth, S., 1985: Growth, development, and feeding success of Atlantic cod larvae Gadus morhua related to egg size. Trans. Am. Fish. Soc. 114, 507-511.

Lagomarsino, I. V.; Francis, R. C.; Barlow, G. W., 1988: The lack of correlation between size of egg and size of hatchling in the Midas cichlid, Cichlasoma citrinellum. Copeia 1988, 1086-1089.

Lasker, R., 1981: The role of a stable ocean in larval fish survival and subsequent recruitment. In: Marine fish larvae. R. Lasker (ed.), Washington Sea Grant Program, Seattle., pp. 80-87.

Marsh, E., 1986: Effects of egg size on offspring fitness and maternal fecundity in the orangethroat darter, Etheostoma spectabile (Pisces. Percidae). Copeia 1986, 18-30.

Miller, T. J.; Crowder, L. B.; Rice, J. A.; Marschall, E. A., 1988: Larval size and recruitment mechanisms in fishes: toward a conceptual framework. Can. J. Fish. Aquat. Sci. 45, 1657-1670.

Miller, T. J.; Herra, T.; Leggett, W. C., 1995: An individual-based analysis of the variability of eggs and their newly-hatched larvae of Atlantic cod (Gadus morhua) on the Scotian Shelf. Can. J. Fish. Aquat. Sci. 52, 1083-1093.

Montgomery, D. C., 1997: Design and Analysis of Experiments. John Wiley; Sons, Inc., New York., pp. 506-535.

Ojanguren, A. F.; Reyes-Gavilán, F. G.; Braña, F., 1996: Effects of egg size on offspring development and fitness in brown trout, Salmo trutta L. Aquaculture 147, 9-20.

Reagan, R. E.; Conley, C. M., 1977: Effect of egg diameter on growth of channel catfish. Prog. Fish-Cult. 39, 133-134.

Rosenthal, H.; Alderdice, D. F., 1976: Sublethal effects of environmental stressors, natural and pollutional, on marine fish eggs and larvae. J. Fish. Res. Board Can. 33, 2047-2065.

SAS Institute, Inc., 1987: SAS/STAT Guide for Personal Computers, Version 6. SAS Institute, Cary, NC, 1028pp.

Sinervo, B., 1990: The evolution of maternal investment in lizards: an experimental and comparative analysis of egg size and its effects on offspring performance. Evolution 44, 279-294.

Sinervo, B.; McEdward, L. R., 1988: Developmental consequences of an evolutionary change in egg size: an experimental test. Evolution 42, 885-899.

Springate, J. R. C.; Bromage, N. R., 1985: Effects of egg size on early growth and survival in rainbow trout (Salmo gairdneri Richardson). Aquaculture 47, 163-172.

Springate, J. R. C.; Bromage, N. R.; Cumaranatunga, P. R. T., 1985 The effects of different rations on fecundity and egg quality in the rainbow trout (Salmo gairdneri). In: Nutrition and feeding in fish. C. B. Cowey, A. M. Mackie and J. G. Bell (eds), Academic Press, London., pp. 371-393.

Ware, D. M., 1975: Relation between egg size, growth, and natura mortality of larval fish. J. Fish. Res. Board Can. 32, 2503-2512. 
Wootton, R. J., 1992: Constraints in the evolution of fish life histories. Netherl. J. Zool. 42, 291-303.

Wootton, R. J., 1994: Life histories as sampling devices: Optimum egg size in pelagic fishes. J. Fish. Biol. 45, 1067-1077.
Author's address: W.-B. Huang, Institute of Zoology, National Taiwan University, Taipei, Taiwan 106, R.O.C. E-mail: d2205010@ccms.ntu.edu.tw 